\title{
DEVELOPMENT OF BIM-SENSOR INTEGRATED PLATFORM FOR MEP PIPING MAINTENANCE
}

\author{
Y. Jing ${ }^{{ }^{*}}$, C. Chen ${ }^{\text {I }}$ L. Tang ${ }^{2}$, H. Xiong ${ }^{1}$ and Y.X. Wang ${ }^{1}$ \\ ${ }^{I}$ Department of Architecture and Built Environment, University of Nottingham, Ningbo, China \\ ${ }^{2}$ Department of Real Estate and Construction, Faculty of Architecture, The University of Hong Kong, Hong Kong, China \\ * Corresponding author
}

\begin{abstract}
In recent years, Building Information Modelling (BIM) has been embraced as the most promising technology to promote the digitalization of global architecture, engineering and construction (AEC) industry. Currently, BIM is mainly applied into the planning, design and construction phase. However, its applications in operation and maintenance (O\&M) is still limited due to the technical barriers in heterogeneous data integration and platform-based collaboration. O\&M is the longest and the most costly phase throughout the building lifecycle, Particularly for Mechanical, Electrical and Plumbing (MEP) systems, which are frequently run in order to provide active services for normal building operations, they are facing the challenges of system component aging and performance deterioration. Therefore, periodic maintenance is required to ensure the normal performance of MEP systems. This study aims to propose a novel development idea of a BIMsensor integrated platform framework for the maintenance management of piping in building MEP systems. The development of the platform not only can link the digital modelling with sensor-based data monitoring and collection to achieve high efficient maintenance for MEP systems, but also can provide services including access, extract, storage, sharing and update of historic maintenance information about building piping. It is hoped that this study can make a contribution to narrowing the gap between the theory of heterogeneous data integration and relevant practical applications, meanwhile give a solution to help address the inconsistency of BIM adoptions in other project phases (such as design, construction, etc.) and in facility management (FM).
\end{abstract}

\section{Introduction}

A case study from Becerik-Gerber et al. (2012) illustrated that there was a large gap between the BIM application level in design and construction stages and that in operation and maintenance stage. As one of the results of this study, in three different building lifecycle stage, there were $83 \%$ of BIM users and $78 \%$ of non-BIM user were interested in BIM application in design stage, $79 \%$ of BIM users and $70 \%$ of non-BIM users were interested in construction stage, and only $42 \%$ of BIM users and $78 \%$ non-BIM users were interested in operation and maintenance stage. It revealed that only approximately half of the BIM users paid attention on potential BIM application in operation and maintenance stage (Becerik-Gerber et al., 2012).

In industry application, Facility Management (FM) was a large-scale concept, which had been defined by International Organization for Standardization in ISO 41011:2017 as "organizational function which integrates people, place and process within the built environment with the purpose of improving the quality of life of people and the productivity of the core business." As a result, the detailed activities in FM was often hard to study in the round. In general, a FM team was combined by a group of Facility Managers, who were responsible to different management objects or activities (International Facility Management Association, 2018). Rather than management activities in space management, occupancy management, technology management and so on, our study focused on the BIM implementation in MEP Services Operation and Maintenance Management. Operation and Maintenance $(\mathrm{O} \& \mathrm{M})$ is a crucial process in equipment lifecycle (Feng C. and Wu P., 2017). As concluded by Liu and Issac in 2013, the cost in O\&M phase contributed about $60 \%$ in the whole facility lifecycle, which mainly consisted of equipment and piping system maintenance and repair at that moment.

\section{Aim and objectives}

This study aims to propose a novel development idea of a BIM-sensor integrated platform framework for the maintenance management of piping in building MEP systems. Performance deterioration is a quite common issue on piping due to material aging, corrosion and blockage. But usually it is not easy for facility managers or inspectors to discover such problems immediately through traditional maintenance way, which can result in system failures. This developed platform integrates BIM with sensors to implement real-time deterioration monitoring and digital modelling. The BIM application can realize a more intuitive representation of piping and building information and make them visualized on a digital model with accurate geometric information to achieve the purpose of facility management. High-performance and low-cost sensors are used in this study to achieve real-time observation and in-time feedback for piping monitoring. 


\section{Literature Reviews}

\subsection{Traditional Maintenance of piping}

The common utilized maintenance methods should be based on some reactive feedback from daily inspection and emergency reports. In practice, these feedbacks are collected from the following channels (Autodesk Ltd., 2019; ARCHIBUS Inc., 2019):

(1) Predictive Maintenance - By sensor (real-time tracking)

(2) Preventive Maintenance - By Maintenance Staff or technician (periodical regular inspection)

(3) Condition Assessment - By occupants surveys

(4) Reactive Maintenance - By occupants or staff (emergency reports)

These maintenance feedbacks can be appropriately divided into 2 types: Planned maintenance (includes the 2 and 3 above) and Failures reacting maintenance (includes the 1 and 4 above)

Theoretically, a conventional MEP maintenance workflow can be recognized as a process of information exchange and treatment: the sensor-BIM integrated platform support FM management to gather the information about the problem in MEP operation (information input), this information can be compared with original design (information treatment), after the comparison result (information output), the member of maintenance team would check source of the problem to get onsite information (information input), the feedback was given back to the FM manager to launch maintenance work (information output), the on-site maintenance work should be record(information input) and give back to the FM manager for re-inspection(information output). This work flow let Facility Manager is the information treatment center to integrate all input information and make appropriate feedbacks.

\subsection{BIM Platform}

The traditional information storage and treatment were based on hardcopy documents, which needed extra investment on documents management and exchange. In order to increase the information exchange and storage efficiency, a computeraided MEP maintenance workflow has been developed well and universally utilized by Facility Management teams. Recent developed FM information integration software are described as CMMS (Computerized Maintenance Management System) (Fiix Inc., 2018), EAMS (Enterprise Asset Management Software) (Fiix Inc., 2018), CAFM (Computer-aided Facility Management) or IWMS (Integrated Workplace Management System) (ARCHIBUS Inc., 2018). Classifying by the functions, CAFM and IWMS are platforms that integrate multiple functions of Facility Management including space management, occupancy management, EAM, operation and maintenance management and so on, when CMMS focuses more on assets and equipment maintenance workflow management (Drawbase Software., 2018). Typical CMMS can function as a core maintenance information storage and treatment center. For instance, one CMMS called Fiix is able to achieve the targets of maintenance activities management, maintenance team management and assets/equipment management, including assign task and activity to management team member, upload the details of task such as equipment, location, contact of respond person etc.

One advanced solution for MEP maintenance workflow management is integrating BIM technology with computerized management systems. The key advantages of BIM utilization in MEP maintenance management can be concluded as follow.

(1) Eliminate the information gap between design \& construction phases and operation \& maintenance phases: Although the CMMS such as Fiix increased the information exchange and treatment efficiency in maintenance phase, the maintenance information database often need to be individually created by O\&M team. A BIM model with high completion level (higher than LOD 350) should be able to supply sufficient information for MEP maintenance works. In other words, the database generated in design phase can be directly delivered to maintenance phase.

(2) Reduce the time for information exchange and maintenance staff training: Because of the visuality of the three dimensional BIM model and the information sticking to the objects in the model, the information pairing between the assets/equipment in reality and objects' data in documents is no more necessary. In the meanwhile, the information contained by a visualized BIM model can be easily understood by untrained staff comparing with tables and written documents. It means the time and manpower costs can both be saved with the usage of BIM.

(3) Possibility of developing new generation of MEP maintenance technologies and workflow: As long as the information related to MEP facilities operation and maintenance conditions is stored in a highly integrated BIM platform, the digital database has the potential to be further developed to build the foundation of smart facility maintenance. For example, the data from the BIM integrated platform can interact with the control signals in building automation systems or building energy management systems to monitor the operation condition of building services (Hu et al., 2018). Moreover, some recent researches have revealed the potential BIM optimization on MEP maintenance workflow including facility maintainability and accessibilities estimating in design phase (Liu R. and Issa R., 2014) and intelligent automatic scheduling for maintenance work orders (Chen W. et al., 2018).

Then, the reasons of why the BIM application in MEP operation and maintenance has not been widely implemented in practice should be analysed. Reorganizing the difficulties of BIM implementation in O\&M phase which listed by Feng and $\mathrm{Wu}$ in 2017 , the following three could be considered as the crucial problems waiting for solutions:

(1) Unclear demand of information for facility operation and maintenance in related BIM model. 
(2) Standardization difficulties in contract, FM software and BIM deliverables.

(3) Lack of direct solution for information exchange between BIM model and FM software such as CMMS or CAFM.

In these problems, the first two should be fundamentally solved by public organizations or policy makers, when the third problem is more technically based. One survey from DLT partner, IMAGINiT Technologies in 2018 demonstrated that the biggest challenge for BIM users in FM was the data integration between the BIM model and FM platform (Bergen G., 2018). In order to solve this problem, some CMMS and CAFM software (BIM 360 OPS, ARCHIBUS, etc.) has already been developed to be able to import the BIM model with commonly used format such as IFC or Revit model. Autodesk BIM 360 OPS is one of the BIM integrated CMMS with best compatibility for Autodesk Revit model. In addition, the function of sensor integrated predictive maintenance is another crucial advantage of BIM 360 OPS (Autodesk Ltd., 2019). Another available method for information exchange is creating a Plugin that connects the objects data in Revit (or other BIM software) and the assets/equipment data in CMMS with MS Excel data sheets (Liu R. and Issa R., 2012).

\subsection{Sensors}

Wireless sensor including humidity sensor, flow sensor, temperature sensor and pressure sensor. is used to send, update, collect and save data under the Bluetooth, WiFi and cellular networks. BIM is required to monitor wireless, wire, simulated building performance data and to amend and visualize the building models.

For sensor selection, there are four application domains of interest sensors can be used: electrical, HAVC, facility management and building controls.

Table 1. Sensor and detected value (Building smart, 2012)

\begin{tabular}{lll}
\hline Sensor type & Detected Value & Applied \\
\hline CO2 sensor & $\begin{array}{l}\text { Concentration of } \\
\text { carbon emissions }\end{array}$ & NO \\
Fire sensor & Fire & NO \\
Smoke sensor & Smoke & NO \\
Sound sensor & Sound level & NO \\
Light sensor & Light & NO \\
Humid sensor & Humidity & YES \\
Moisture sensor & Moisture content & YES \\
Temperature & Temperature & YES \\
sensor & & \\
Pressure sensor & Pressure & YES \\
Gas sensor & Gas amount & NO \\
Movement & Movement & NO \\
sensor & & \\
Flow sensor & Flow rate & YES \\
\hline
\end{tabular}

The logic chain of the linking between all MEP components including HAVC system, plumping system, electrical and security system and sensor is shown below.

Real-time monitoring data from the sensor can be recorded by BIM graphically or statistically. The monitoring records based on the sensor is converted into standard and uniform data that are generated by the BIM system. For instance, the water flow data can be monitored by water supply system and integrated with BIM system and displayed graphically. Real-time displayed data shows the different flow speed which are colored differently seen in figure below.

Figure 1. Real-time display data shows the flow speed of water (Hu et al., 2018)

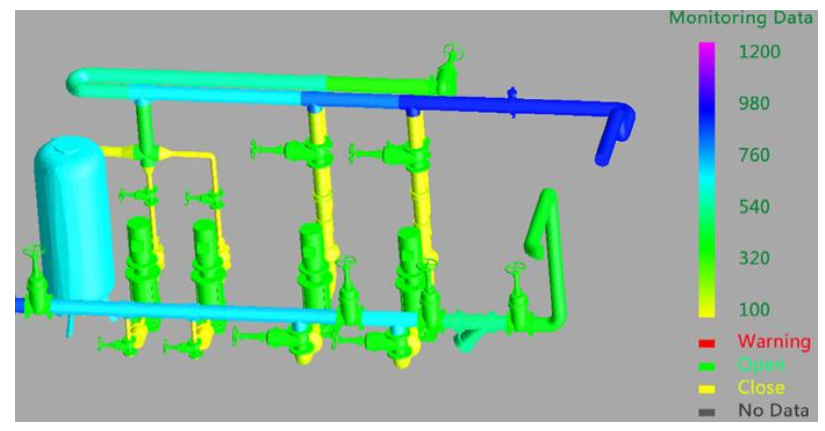

\subsection{Data exchange}

There are generally 6 data exchange standards in AEC Industry provided by Autodesk (2011) shown below:

Table 2. Data exchange standards

\begin{tabular}{ll}
\hline Standard & Application \\
\hline IFC & $\begin{array}{l}\text { Construction and facilities } \\
\text { management }\end{array}$ \\
gbXML & $\begin{array}{l}\text { Energy } \\
\text { design and survey } \\
\text { measurement data }\end{array}$ \\
Land XML & Exchange 2d design in \\
& CAD \\
Dwg & 3D production for Revit \\
& family \\
SAT & Exchange it with Bentley \\
\end{tabular}

As this study focuses on the facility management, IFC (Industry Foundation Classes) is an appropriate data format that can be adopted in this study due to its advantages in open global standard, multiple LOD, high geometric and semantic supports for describing, sharing and exchanging information about construction and facilities management (Chen and Clarke, 2017). Currently IFC is supported by over 150 software venders and organizations all over the world (NBS, 2017).

The IFC is potential for representing the building performance. Ifc Sensor defines an occurrence of sensor. The Ifc Sensor Type is connected to other elements, such as, flow element for water pipes and air flow pipes. 
The original IFC files should be uploaded on the BIM platform. The objective of this step is to translate the IFC files to the interactive web documents. The information gathered from the monitoring of MEP system including pressure, temperature, humidity and flow rate is obtained via sensors. The IFC model can be used to upload the data on a BIMserver which is associated with some small IFC files from sensor. Therefore, the sensor data can be stored in relevant IFC objects and handled by BIMserver.

Furthermore, there is a tool developed by Zhang et.al for implementing 3D presentations and IFC parsing during the process. IFC file data are parsed and then they are converted into real-time dynamic data that are mapped to smart sensors due to the insertion of adapter layer.

\section{Methodology}

Figure 2 shows the overall methodology for this study. Through the literature reviews of traditional way in piping maintenance operation, the existed BIM platforms for piping maintenance management, find out the deficiencies and improvement solution for them, and the work principle of piping sensors, and the data transferring, The BIM tools Revit and Navisworks were selected for providing the basic nonclash model for the platform, then Data transforming principle based on IFC was studies to be applied for transferring the dynamic sensor data in the designed BIM platform. After the platform is applied into real case studies for validation, it is possible to determine whether such a BIM platform is feasible for practical applications in FM.

Figure 2. Overall methodology for the study

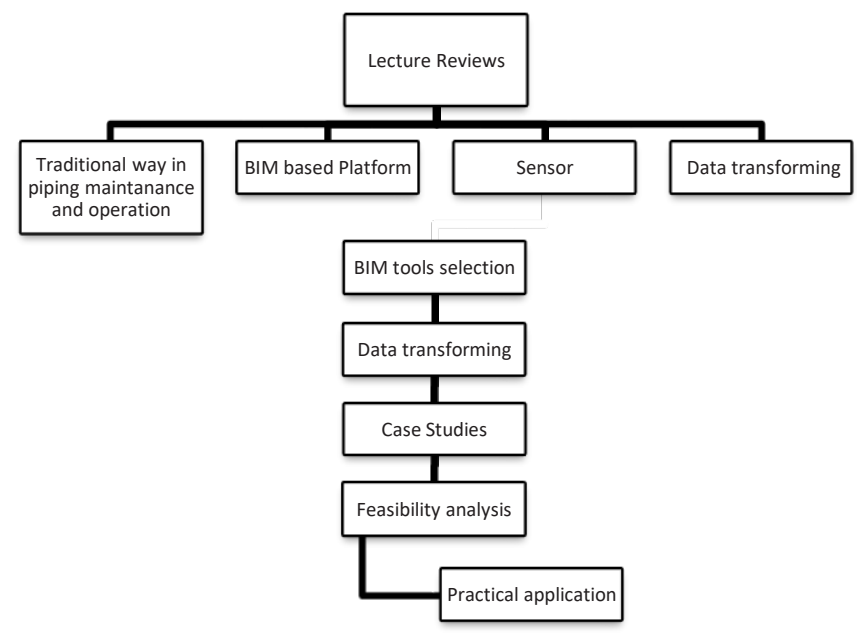

\section{Development of platform}

In theory, the BIM-sensor integrated platform should supply appropriate and straightforward information for the Facility Manager and all related maintenance staff. As a trial version of platform, Figure 3 illustrates the operation condition and maintenance information of a HVAC pipe) on an operation interface of the mobile version BIM-sensor integrated platform. It means the compressed 3D-BIM model and its information, which are needed for maintenance workflow management, can be reviewed and amended (if with proper access authorization) on mobile terminals. The trial version of platform can achieve the functions as listed below:

(1) Searching for the target equipment or room: Press the "Show Rooms" button and select the required elements from the BIM database.

(2) Real-time tracking the operation conditions of the target elements: In the module of "Facility Operation Data", related operation parameters that monitored by sensors will be automatically refreshed once per 30 seconds, so that the Facility Manager and related staff can immediately gather the abnormal signals and make feedbacks as soon as possible.

(3) Reviewing the previous error logs: All recent errors happened in the target equipment and pipes will be stored in "Error Log" documents.

(4) Checking the degree of completion of todays' maintenance work: The work schedule for today's maintenance plan will be uploaded by the Facility Manager. Then, the maintenance staff can check to complete each work according to the schedule plan.

Figure 3. Operation interface of mobile version BIMsensor integrated platform (draw by author)

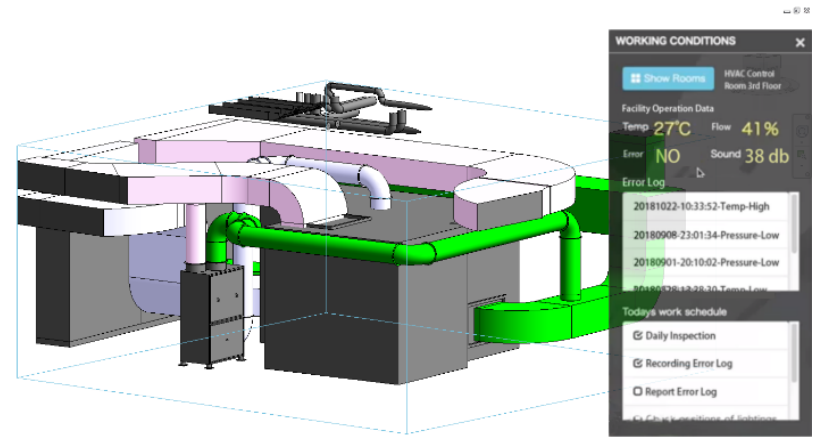

\section{Conclusion}

In conclusion, based on the comparison of existing BIM data platforms and the study of traditional MEP management, the existing sensor researches and data exchange principles on the market, this study provides an innovative idea to real-time monitoring framework for operations and maintenance based on a heterogeneous data integration of BIM with sensors for FM purpose of traditional MEP systems.

However, there are still some limitations in this study. From the economic point of view, this framework is limited by the cost of the sensor, the cost of the workstation data manager and the daily sensor maintenance of the platform. As for standard perspective, it is necessary to apply a relevant consistent data standard or implement regulations manuals to ensure 
consistency of future operations. Additionally, the interoperability between different data systems and the integration of data is one of the limitations. Although the IFC standard was selected in this paper, the instruction manual of relevant industry standard is needed. Furthermore, localization is also a problem worth exploring due to the differences in the needs of different countries and regions requires a local guide to adapt to specific conditions.

But it cannot be denied that this study still makes a significant contribution to narrowing the gap between the theory of heterogeneous data integration and relevant practical applications, meanwhile give a solution to help address the inconsistency of BIM adoptions in other project phases (such as design, construction, etc.) and in facility management (FM). The developed integration platform can be further improved through technical simplifications and empirical data collections from more relevant case studies.

\section{Acknowledgements}

The work presented in this research study was undertaken by the aegis of the BIM-GIS Application in Green Built Environment Project, funded by the Ningbo Science and Technology Bureau (2015B11011).

\section{References}

Autodesk Ltd. (2019) Building Maintenance Management | $\begin{array}{llll}\text { Autodesk } & \text { BIM } & 360 & \text { Ops. }\end{array}$ https://bim360ops.autodesk.com/product (accessed 06/01/2019).

ARCHIBUS Inc. (2018) What is IWMS? | ARCHIBUS. https://archibus.com/glossary/integrated-workplacemanagement-system/ (accessed 06/01/2019).

ARCHIBUS Inc. (2019) Building Operations | ARCHIBUS. https://archibus.com/products/building-operations/ (accessed 02/01/2019).

Barnaghi P et al. (2009) Sense and sensability: semantic data modelling for sensor networks. In ICT Mobile Summit.

Becerik-Gerber B et al. (2012) Application Areas and Data Requirements for BIM-Enabled Facilities Management. Journal of Construction Engineering and Management, 138(3), pp. 431-442. doi: 10.1061/(ASCE)CO.19437862.0000433.

Bergen G (2018) 10 Things Your Facilities Management Team Can Do to Rock in the Field - DLT Blog. http://www.dlt.com/blog/2018/02/28/10-facilitiesmanagement-team-rock-field/ (accessed 08/01/2019).

BuildingSMART (2012)

http://buildingsmart-

tech.org/ifc/IFC2x3/TC1/html/index.htm. 08/01/2019).

(accessed

Cadac Group (2018) BIM for operations \& maintenance and FM - Cadac Group. https://www.cadac.com/en/themes/bimfor-operations-maintenance-and-fm/ (accessed 05/01/2019).
Capricot Technologies Pvt. Ltd. (2014) BIM for Operation and Facility management - YouTube. https://www.youtube.com/watch?v=MUMRHiaqI8Q (accessed 06/01/2019).

Chen J and Clarke KC (2017) Modeling Standards and File Formats for Indoor Mapping. Proceedings of the 3rd International Conference on Geographical Information Systems Theory, Applications and Management (GISTAM 2017), pp. 268-275. doi: 10.5220/0006364202680275.

Chen W et al. (2018) BIM-based framework for automatic scheduling of facility maintenance work orders. Automation in Construction. Elsevier, 91, pp. 15-30. doi: 10.1016/J.AUTCON.2018.03.007.

Dispenza K (2011) BIM: Bridging the Gap between AEC and O\&M. http://buildipedia.com/aec-pros/facilities-opsmaintenance/bim-bridging-the-gap-between-aec-and-om (accessed 05/01/2019).

Drawbase Software (2018) Drawbase | Facility Management Software. http://unbouncepages.com/drawbase$\mathrm{gdm} /$ ?directory=facility_management\&utm_source=capterra (accessed 06/01/2019).

El-Ammari KH (2006) Visualization, data sharing and interoperability issues in mod-el-based facilities management systems. Ph.D. thesis. Concordia University.

Feng CW and Wu PC (2017) Constructing a MEP BIM Model Under Different Maintenance Scenarios-A Case Study of Air Conditioning. 34th International Symposium on Automation and Robotics in Construction. See http://www.iaarc.org/publications/fulltext/ISARC2017Paper031.pdf (accessed 20/12/2018).

Fiix Inc. (2018) What is a CMMS? | Fiix. https://www.fiixsoftware.com/cmms/ (accessed 06/01/2019).

Fiix Inc. (2018) What is EAM Software? Fiix. https://www.fiixsoftware.com/eam/ (accessed 06/01/2019).

$\mathrm{Hu} \mathrm{ZZ}$ et al. (2018) BIM-based integrated delivery technologies for intelligent MEP management in the operation and maintenance phase. Advances in Engineering Software. Elsevier, 115, pp. 1-16. doi: 10.1016/J.ADVENGSOFT.2017.08.007.

International Facility Management Association (2018) What is FM - Definition of Facility Management. See https://www.ifma.org/about/what-is-facility-management (accessed 05/01/2019).

International Organization for Standardization (2017) ISO 41011-2017: Facility Management - Vocabulary. See https://www.iso.org/standard/68167.html (accessed 05/01/2019).

Liu R and Issa RRA (2012) Automatically Updating Maintenance Information from a BIM Database. International Conference on Computing in Civil Engineering. June 2012, pp. 373-380. doi: 10.1061/9780784412343.0047.

Liu R and Issa RRA (2013) Issues in BIM for Facility Management from Industry Practitioners Perspectives. Computing in Civil Engineering, (June), pp. 411-418. doi: 10.1061/9780784413029.052. 
Liu R and Issa RRA (2014) Design for maintenance accessibility using BIM tools. Facilities, 32. doi: 10.1108/F09-2011-0078.

Patel H (2016) BIM for MEP Installation and Maintenance | The BIM Hub. See https://thebimhub.com/2016/10/17/bimfor-mep-installation-maintenance/\#.XDiQa84zaU1 (accessed 07/01/2019).

Totalbimconsulting.com (2018) BIM for operation and facility management $\mid$ Total BIM Consulting. http://www.totalbimconsulting.com/en/services/bim-foroperation-and-facility-management (accessed 05/01/2019)

Zhang J et al. (2015) Building Information Modelling for Smart Built Environments. Buildings. doi: 10.3390/buildings 